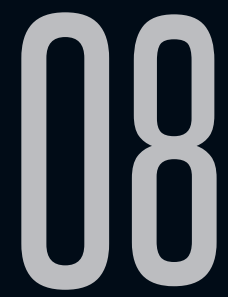

\title{
A CONSTRUÇÃO DE MONSTROS EM JOGOS VORAZES
}

Cássia Farias (UFF)

Recebido em 15 jan 2020. Cássia Farias é Mestre em Estudos de Literatura Aprovado em 11 mai 2020. Literaturas Estrangeiras Modernas pela Universidade Federal Fluminense. Doutoranda em Literatura Comparada pela UFF. Pesquisa literatura juvenil em língua inglesa e atualmente trabalha com as obras distópicas escritas para esse público. Lattes: http://lattes.cnpq.br/7125901648297685. E-mail: cassiafarias@gmail.com

Resumo: Um dos elementos do Gótico que frequentemente pode ser encontrado nas distopias é a monstruosidade. O Gótico, desde suas origens, trata de ansiedades culturais e aparece como uma reação às transformações sociais decorrentes da modernidade (BOTTING, 2005) - nesse sistema, o monstro funciona como uma representação dessas preocupações ao ameaçar a ordem. Tendo isso em mente, o objetivo deste artigo é analisar como a monstruosidade se faz presente na trilogia Jogos Vorazes (2008-2010), de Suzanne Collins, abordando como esses monstros são construídos e qual o seu papel nas narrativas, a fim de estabelecer o que eles revelam sobre a sociedade representada nos romances.

Palavras-chave: Gótico; distopia; monstro; Jogos Vorazes. 


\begin{abstract}
One element of the Gothic that can be frequently identified in dystopias is monstrosity. Since its origins, the Gothic deals with cultural anxieties and appears as a reaction to the social changes brought by modernity (BOTTING, 2005) - in this scenario the monster functions as a representation of these concerns by acting as a threat to the order.. With this in mind, the goal of this article is to analyze how monstrosity is representanted in The Hunger Games trilogy (2008-2010), by Suzanne Collins, touching on how these monsters are created and their roles in the narrative, in order to establish what they reveal about the society of the novels.
\end{abstract}

Keywords: Gothic; dystopia; monster; The Hunger Games.

\title{
INTRODUÇÃO
}

As vertentes literárias da distopia $^{1}$ e do Gótico parecem caminhar lado a lado, sendo possível observar uma apropriação de elementos da estética gótica em diversas obras de cunho distópico, como 1984 de George Orwell e O conto da aia, de Margareth Atwood. As relações entre as duas vertentes também se estendem a algumas de suas características básicas. O Gótico, desde suas origens, trata de ansiedades culturais e aparece como uma reação às transformações sociais decorrentes da modernidade (BOTTING, 2005, p.1-2), ressurgindo em períodos de crise epistemológica e se modificando de acordo com o momento histórico. Influenciada por pensadores do século XX, como Foucault, que questionavam crenças humanistas e o próprio pensamento utópico, uma das

1 Não é o objetivo desse artigo discutir qual é a definição mais adequada do que seriam distopias, se é melhor chamar o conjunto dessas obras de gênero ou de vertente literária. Por uma questão de conveniência e para os propósitos desse trabalho, irei abordá-las como uma vertente com alguns procedimentos estéticos próprios, e um dos objetivos do trabalho é mostrar como alguns desses elementos se relacionam com o gótico. 
definições mais difundidas da distopia afirma que ela se caracteriza por representar "sociedades não existentes, descritas com considerável detalhe, localizadas em um espaço-tempo que o autor tem a intenção de que seja percebido por um leitor contemporâneo como consideravelmente pior do que a sociedade em que aquele leitor vive" (SARGENT, 1994, p.9)². A distopia aparece como a representação de um lugar exacerbadamente negativo e que deve ser evitado pois geralmente representa a corrupção de ideais ou valores, o que também encontra correlação no fato de que a "a escrita Gótica permanece fascinada com objetos e práticas que são construídos como sendo negativos, irracionais, imorais e fantásticos" (BOTTING, 2005, p.1). ${ }^{3}$ Em seus fundamentos, a distopia e o Gótico são marcados por apresentar um cenário que parece afastado da realidade empírica do leitor mas que tem por objetivo discutir a condição do mundo em que ele vive. Nos dois casos, temos a figuração dos medos referentes à época de produção, cujo objetivo é fazer uma crítica do presente, alertando para as suas falhas e seus perigos.

Para além dessas questões basilares, existem diversos elementos estéticos, formais e estruturais provenientes do Gótico que podem ser observados nas obras distópicas. Um desses elementos é a figura do monstro. Punter e Byron apontam que "[e]timologicamente falando, o monstro é algo para ser mostrado, algo que serve para demonstrar (Latin, monstrare: demonstrar) e

2 Todas as traduções de obras em língua estrangeira são de minha autoria. No original: "non-existent society described in considerable detail and normally located in time and space that the author intended a contemporaneous reader to view as considerably worse than the society in which that reader lived."

3 No original: "Gothic writing remains fascinated by objects and practices that are constructed as negative, irrational, immoral and fantastic" 
alertar (Latin, monere: alertar)" (2004, p.263) ${ }^{4}$, sendo comumente interpretado como um arauto da vontade superior e de possíveis desastres. A partir do século 18, com o advento do Gótico, "a aparência horrífica do monstro começou a servir uma função cada vez mais moral"5 (2004, p.263), promovendo comportamentos virtuosos ao mostrar os riscos do vício e da insensatez. O monstro, então, faz parte do mecanismo de crítica e de reflexão do Gótico, e, sendo assim, não é de se estranhar que ele se faça tão presente em narrativas distópicas. Um exemplo de obra desse gênero em que essa presença pode ser sentida é a trilogia Jogos Vorazes $(\mathrm{s})^{6}$ (2008-2010), de Suzanne Collins: ao longo da narrativa, temos diversas figuras que se tornam monstruosas, e que parecem ser fundamentais para a construção e manutenção daquela sociedade. Partindo desse ponto, o objetivo desse trabalho é analisar como a monstruosidade se faz presente na série, posicionando essas figuras em dois grandes grupos - aquelas que revelam uma relação entre o monstro e o poder, e as que colocam a monstruosidade como a perda da humanidade. A fim de estabelecer o que esses seres revelam sobre a sociedade ali representada, será abordado o processo de construção desses monstros, partindo da definição de monstruosidade proposta por Carroll (1999), bem como a função que eles exercem na narrativa, tendo como base os trabalhos de Cohen (2000) e Punter e Bryon (2004).

4 No original: "[e]tymologically speaking, the monster is something to be shown, something that serves to demonstrate (Latin, monstrare: to demonstrate) and to warn (Latin, monere: to warn)"

5 No original: "the horrific appearance of the monster had begun to serve an increasingly moral function"

6 Quando (s) aparecer ao lado do título, entende-se que é uma referência à série como um todo, e não ao primeiro livro, que lhe é homônimo. 


\section{ESTADO E MONSTRUOSIDADE}

A história da série se passa em Panem, uma sociedade fechada que se encontra sob um poder totalitário, apresentando características comuns a esse tipo de regime, como repressão violenta e uma vigilância intensa. O país é dividido em doze distritos e a Capital, sede e símbolo do poder e do Estado. Anualmente, a Capital organiza os Jogos Vorazes, uma competição em que adolescentes são escolhidos para representar os distritos em uma batalha até a morte da qual apenas um sairá vivo. Ao longo da trilogia, vemos horrores comuns a sociedades distópicas, e somos também apresentados a uma série de figuras monstruosas.

Inicialmente, é preciso abordar a noção de monstro apresentada em A filosofia do horror ou paradoxos do coração, onde Carroll propõe que, para provocar o horror-artístico, o monstro deve ser, ao mesmo tempo, ameaçador e impuro. As figuras monstruosas representam um risco para a integridade física e/ou psicológica do sujeito, podendo também representar uma ameaça moral ou social, decorrente de seu potencial de abalar e destruir as estruturas conhecidas do interior do indivíduo e de seu meio (CARROLL, 1999, p.64). Para tratar da outra dimensão do monstro, Carroll traz, em seu texto, a ideia de Mary Douglas de que a impureza está relacionada com "a transgressão ou a violação de esquemas de categorização cultural" (1999, p.50), e um ser pode ser assim classificado caso seja "categoricamente intersticial, categoricamente contraditório" (1999, p.50), que causa uma confusão cognitiva, sendo visto como uma "repulsiva e repugnante" (1999, p.38) violação da natureza. Somando esses dois aspectos do monstro, tem-se que a reação 
inspirada pelas figuras monstruosas nas histórias de horror "não é simplesmente uma questão de medo, ou seja, de ficar aterrorizado por algo que ameaça ser perigoso. Pelo contrário, a ameaça misturasse à repugnância, à náusea e à repulsa." (1999, p.29). As estratégias de produção de monstros nessas narrativas, então, vão se relacionar com essas características.

Carroll trata especificamente do monstro no contexto do horror sobrenatural, enquanto um ser que existe fora da concepção de real do contexto de produção, o que a princípio impediria a utilização dessa teoria no que se refere às distopias não fantásticas. Apesar do recorte, alguns elementos permitem traçar um paralelo entre os dois gêneros, e muitos dos elementos usados na distopia parecem remeter a Carroll. O primeiro deles diz respeito justamente aos sentimentos que o monstro provoca. Para o autor, o horror é um estado emocional do tipo que

tem dimensões tanto físicas quanto cognitivas. De um modo geral, a dimensão física de uma emoção é uma agitação sentida. Especificamente, a dimensão física é uma sensação ou um sentimento. Ou seja, uma emoção envolve uma espécie de excitação, de perturbação ou de suspensão, fisiologicamente marcada por uma aceleração do batimento cardíaco, da respiração e de reações assemelhadas. (CARROLL, 1999, p.41)

Tanto a dimensão cognitiva quanto a física são representadas na narrativa através dos personagens e suas reações aos monstros, sendo a última frequentemente manifestada por meio de arrepios, gritos e outros gestos que podem ser lidos como uma reação de susto. Carroll afirma que o que separa uma obra de horror de meras 
narrativas que contêm monstros são "as respostas afetivas dos personagens humanos positivos das histórias aos monstros que os assediam." (1999, p.32). A resposta das personagens se relaciona diretamente com

as respostas emocionais que as obras de horror tencionam provocar no público, pois o horror se revela um desses gêneros em que as respostas emocionais do público, idealmente, correm paralelas às emoções dos personagens. De fato, nas obras de horror, as respostas dos personagens muitas vezes parecem sugerir as respostas emocionais do público. (CARROLL, 1999, p.32)

Carroll aponta que "a obra de horror artístico tem embutido dentro de si, por assim dizer, um conjunto de instruções acerca da maneira adequada como o público deve responder a ela" (1999, p.49), e algo semelhante costuma ocorrer em narrativas distópicas. Um elemento importante para delimitar se uma obra pode ou não ser considerada uma distopia é justamente "a identificação que o leitor é convidado a sentir pelo narrador/personagem [,u]ma vez que é o protagonista que vive a sua sociedade como distópica" e é "a compreensão que o leitor tem da mensagem do narrador que vai estabelecer a distinção entre o que constitui um mundo futuro 'bom' ou 'ruim'”' (VARSAM, 2003, p.205)7.

Temos, então, duas vertentes literárias em que a perspectiva apresentada na narrativa costuma carregar um tom de julgamento e condenação moral, e onde se espera que o leitor se identifique com a visão da personagem e a tome para si. As distopias almejam 7 No original: "the identification the reader is invited to make with the protagonist/ narrator [, s]ince it is the protagonist who experiences his/her society as dystopian" e "the reader's understanding of the narrator's message that will establish the distinction between what constitutes a 'good' or a 'bad' future world" 
construir uma crítica social, e o que acontece, nessa e em outras narrativas, é que certos elementos são intensificados e exagerados justamente para que o leitor passe a vê-los como problemáticos, e atente para os riscos de deixar que se perpetuem. Uma maneira de conseguir esse efeito é fazer com que esses elementos se tornem monstruosos - provocar horror através da monstruosidade, então, pode ser sim uma estratégia da distopia. As ideias de Carroll são interessantes para esse trabalho pois, no que se refere a Jogos Vorazes (s), as personagens seguem um padrão de reação bastante semelhante ao descrito por ele, incluindo o aspecto físico. Para fins desse artigo, então, estamos lidando com uma adaptação da teoria carrolliana que extrapola alguns de seus conceitos. Um dos motivos para isso é o fato de que muito do que Carroll descreve sobre o processo de criação de monstros pode ser visto na forma como as figuras monstruosas são representadas na trilogia de Collins.

Uma entidade que adquire ares monstruosos na narrativa é justamente o Estado. Cartwright aponta que, em algumas distopias que apresentam elementos góticos, uma das categorias básicas de monstruosidade que se faz presente é o "mal do estado/maquinário ideológico" (2005, p.181) ${ }^{8}$. O Estado já poderia ser entendido como uma força monstruosa por conta de sua crueldade e do extremismo de seus atos: Katniss, a narradora e protagonista da história, convida o leitor a enxergar sua realidade como horrível. O que ocorre é que esse horror é um resultado direto do domínio exercido pela Capital, o que faz com que a própria instituição de poder seja a fonte desse sentimento - visão corroborada ao longo da série por outras personagens.

8 No original: "evil of the state/ideological machinery" 
Na construção desse efeito, é possível perceber elementos de uma das estratégias de conformação de monstros proposta por Carroll, a da magnificação, que consiste em aumentar as dimensões de seres que já possuem um potencial para causar desconforto no público.

Os eventos ${ }^{9}$ e atos que os personagens colocam como monstruosos mantêm relação com a nossa realidade, e podemos sim dizer que, o que vemos aqui ampliado, são tendências observáveis em nossa sociedade "já potencialmente perturbadoras e repugnantes" (CARROLL, 1999, p.72), estando presentes em muitas relações de poder e exploração na contemporaneidade. A magnitude, nesse contexto, se refere também à dimensão do poder em si, o que pode ser melhor observado na figura do líder dessa sociedade.

Panem está há vinte e cinco anos sob o comando do presidente Snow, um ditador que, ao longo da série, ganha ares de Grande Irmão, ao se mostrar capaz de vigiar e de se fazer presente em uma diversidade de lugares - com a diferença de que, na série, é inegável a sua presença física, ao contrário da figura de $1984^{10}$, que provavelmente não passa de uma invenção do Partido. Snow entraria no grupo de personagens que Cartwright diz que "personifica a monstruosidade do estado: invasiva e totalitária" (2005, p.205), pois não só o representa como ativamente age para

9 Carroll é enfático em dizer que o art-horror não vem de eventos, mas sim de entidades. Como estamos lidando com uma adaptação da teoria, podemos interpretar os eventos aqui como manifestação direta da entidade monstruosa do Estado.

10 A obra de Orwell é de extrema importância no universo das distopias, por ser um dos romances que ajudou a consolidar essa vertente, sendo uma grande influência até hoje. No livro, temos um governo ditatorial centrado na figura do Grande Irmão, que funciona como um forte símbolo do poder de vigilância do partido, mesmo que sua existência seja metafórica. 
sua manutenção. Tal como Snow parece estar presente e saber o que acontece em todos os lugares, o poder do governo é tão amplo e extenso que ele parece permear todos os aspectos da vida dos indivíduos, que se sentem constantemente vigiados, e, de fato, o são em muitos momentos.

A figura de Snow incorpora ainda as ideias de impureza e de repelência que Carroll julga serem primordiais para que o monstro provoque horror. Carroll afirma que "os seres horríficos estão muitas vezes associados à contaminação - doença, enfermidade e peste - e não raro são acompanhados de animais infectados - ratos, insetos e que tais" (1999, p.46) e que coisas que rastejam são excelentes candidatas a serem objetos do horror, justamente por já serem consideradas repugnantes (1999, p.71). A construção da figura do presidente brinca com esses elementos, sendo que ele é descrito como tendo "olhos de serpente" (COLLINS, 2011, p.24), e esse elemento reptiliano é tão marcante que afeta a reação das pessoas a ele:

[t]rato-o como se fosse uma verdadeira cobra, do tipo venenoso. Fico imóvel, olhos grudados nele, avaliando as possibilidades de uma fuga. (COLLINS, 2011, p.26)

O presidente Snow sorri e reparo em seus lábios pela primeira vez. Estou esperando lábios de serpente, o que significa nenhum lábio. Mas os dele são grossos, a pele bastante esticada. Sou obrigada a imaginar se sua boca foi modificada para fazer com que ele ficasse mais atraente. Se for o caso, foi uma perda de tempo e dinheiro porque ele não é nem um pouco atraente. (COLLINS, 2011, p.26)

Os olhos conferem tamanha repugnância a sua aparência que Katniss espera que outros elementos do rosto do presidente 
também pareçam com os de uma cobra, e a presença dele afeta sua cognição de tal maneira que ela não conhece outra forma de reagir a ele que não seja tratá-lo como uma animal ameaçador.

Snow também é relacionado com a contaminação e a doença. Na ocasião desse encontro, Katniss sente um forte odor de rosas misturado com sangue, não conseguindo identificar a origem desse último, até que o presidente se aproxima dela, e a jovem percebe que o cheiro vem de seu hálito. No terceiro livro, descobrimos que o presidente anda sempre com uma flor na lapela justamente para disfarçar o aroma de sangue, proveniente de feridas em sua boca que nunca se curam - resultado da ingestão de veneno, "[a] arma perfeita para uma cobra" (COLLINS, 2011b, p.188) ${ }^{11}$.

Na cena, Snow dá uma demonstração de sua onipresença e onisciência, revelando para Katniss a dimensão do poder de vigilância e conhecimento que detém sobre as ações da jovem - tudo isso para forçá-la a seguir suas ordens, e ir contra seus sentimentos. Sobre a sua reação à figura de Snow, Katniss diz: "Minha ojeriza em relação a essa conversa, a discutir com o presidente Snow meus sentimentos por duas das pessoas que mais estimo, faz com que minhas palavras saiam engasgadas" (COLLINS, 2011, p.31), confirmando a aversão que esse poder total - aqui representado por Snow - produz.

A magnificação pode então ser associada à já mencionada tendência da distopia de intensificar e exagerar elementos como forma de provocar revolta e reflexão. As relações entre monstruosidade e o poder/Estado em Jogos Vorazes (s), porém, não

11 Snow colocava veneno em alimentos e bebidas para eliminar seus oponentes políticos e desafetos, e ingeria ele mesmo o veneno para despistar suspeitas. 
se limitam a isso. O que diferencia a série de outras distopias, e que é de especial interesse para este artigo, é o fato de que esse estado monstruoso se ocupa, por sua vez, em criar seus próprios monstros - esses mais afins às criaturas próprias do horror.

É preciso mencionar, sobre a trilogia, que esse processo de construção de monstruosidades parece estar diretamente ligado a estratégias de controle e dominação. Um elemento central das distopias é o controle do corpo e dos sujeitos, que se faz primordial para a manutenção do regime. Isso é alcançado, no geral, pela criação de corpos dóceis. O conceito, originalmente proposto por Michel Foucault (1999, p.118), descreve um corpo que "pode ser submetido, que pode ser utilizado, que pode ser transformado e aperfeiçoado", e é frequentemente usado quando se discutem distopias, uma vez que esse processo também pode ser visto nas relações entre os sujeitos e o poder em diversas obras. Para o pensador, as disciplinas, meios pelos quais o corpo é docilizado, visam "não unicamente [a]o aumento de suas habilidades, nem tampouco aprofundar sua sujeição, mas a formação de uma relação que, no mesmo mecanismo, o torna tanto mais obediente quanto é mais útil, e inversamente" (FOUCAULT, 1999, p.119). O que a leitura de Jogos Vorazes (s) indica, porém, é que esses corpos se tornam mais obedientes e mais úteis na medida em que eles vão se tornando menos capazes de reagir. Uma das formas de fazer com que os sujeitos atinjam essa complacência é através do uso de monstros.

No mundo da trilogia, existem seres chamados de bestantes, animais geneticamente modificados e criados para servirem como armas pelas instâncias de controle, sendo utilizados para 
cumprir os mais diferentes propósitos, desde um facilitador de ações na arena até um mecanismo de espionagem. Enquanto alguns desses seres têm a aparência de animais normais, outros se aproximam mais da imagem convencional do monstro de aparência assustadora, como os bestantes que aparecem perto do final do primeiro livro. Ao final dos Jogos Vorazes, Katniss e Peeta estão se preparando para enfrentar Cato, o sobrevivente restante, quando percebem que ele está fugindo de um bando de criaturas.

À medida em que se juntam, erguem-se novamente para se pôr facilmente sobre as pernas traseiras, 0 que dá a elas uma aparência fantasmagoricamente humana. Todas possuem uma pelagem espessa, algumas com pelos retos e lisos, outras com pelos ondulados, e as cores variam entre o preto retinto e o que só posso descrever como louro. Há uma coisa a respeito delas, uma coisa que faz os cabelos em minha nuca se eriçarem, mas eu não posso colocar meus dedos lá. (COLLINS, 2010, p.354-355)

Katniss sente um arrepio, uma reação física muito recorrente frente a uma presença monstruosa e que, como dito anteriormente, indica para o leitor o que essas figuras devem inspirar (CARROLL, 1999, p.32), mas mais do que repulsa ou medo, o que ela experimenta é uma inquietação. Katniss logo percebe o motivo dessa sensação:

Os olhos verdes que brilham pra mim não são iguais ao de nenhum cão ou lobo, ou qualquer outro animal canino que eu jamais tenha visto. Eles são eminentemente humanos. Estou quase registrando a revelação quando reparo o colar com o número 1 adornado com joias, e todo o 
horror me atinge como um raio. O cabelo louro, os olhos verdes, o número... é Glimmer.

Um grito me escapa da boca. (COLLINS, 2010, p.354-355)

O incômodo sentido por ela se origina do fato de que havia algo de familiar naquelas criaturas, porque de fato, Katniss já havia se encontrado com cada uma delas - elas nada mais eram do que os outros participantes dos jogos que já haviam morrido. A jovem demora alguns momentos para perceber isso, mas quando tem a revelação é tomada por um sentimento de horror tão forte que solta um grito, se tornando também capaz de distinguir em cada criatura os traços da pessoa em cima da qual foram construídas, e as reconhecendo. A criação desses bestantes está de acordo com a ideia de Carroll de que o monstro precisa ser impuro, o que pode ser conseguido através da mistura de espécies - como humano e animal, tal como se observa nas citações. É justamente essa mistura de categorias, algo que ao mesmo tempo é familiar e estranho, humano e não mais humano, que torna o bestante ainda mais horrível e provoca uma reação tão visceral em Katniss.

Podemos ver também, nas citações, a estratégia denominada fusão por Carroll, que consiste justamente na "construção de criaturas que transgridem distinções categóricas como dentro/fora, vivo/morto, inseto/humano, corpo/máquina, e assim por diante" (1999, p.64), cuja principal característica é "a mistura de categorias normalmente separadas ou conflitantes num indivíduo integral, espaço-temporalmente unificado" (1999, p.65). Essa estratégia também é usada na criação de outro bestante, que Katniss encontra perto do final da série: 
Eles são brancos, possuem quatro membros, têm mais ou menos o tamanho de um ser humano adulto, mas as comparações param por aí. Nus, com longos rabos reptilianos, costas arqueadas e cabeças protuberantes. (COLLINS, 2011b, p.332)

[D]ou uma boa olhada neles. Uma mistura de seres humanos e lagartos e sabe-se lá mais o quê. Pele branca e firme de répteis salpicada de sangue, mãos e pés com garras, seu rosto uma mistura de características conflitantes. Sibilando, berrando meu nome agora, enquanto seus corpos se contorcem em fúria. Debatendo-se com rabos e garras, arrancando pedaços uns dos outros ou de si mesmos com bocas grandes e espumosas, enlouquecidos pela necessidade de me destruir. (COLLINS, 2011b, p.334)

Mais uma vez temos a mistura de humano e animal, uma combinação de elementos que causa confusão e desconforto. Esses seres também desafiam a lógica e o sentido, pois na busca por seu objetivo - destruir Katniss - eles passam por cima da polícia da Capital e atacam os outros do grupo e até mesmo o próprio corpo, sem que isso pareça afetar sua eficiência e sua ação. A jovem sabe que os "homens-lagartos" direcionam o seu ataque a ela, o que é uma espécie de confirmação a algo sobre o que ela já havia se questionado antes ao encontrar os bestantes na arena:

E o cérebro? Será que essas bestas receberam alguma lembrança dos tributos reais? Será que foram programadas para odiar especialmente nossos rostos porque sobrevivemos e eles foram assassinados de maneira tão cruel? E os que matamos de fato...será que acreditam que estão vingando sua própria morte? (COLLINS, 2010, p.356) 
Essas impressões não são uma paranoia de Katniss. Mesmo que o cenário possa não ser exatamente como ela imagina, a verdade é que, nos dois casos, existem pessoas por trás dos bestantes, não só construindo essas criaturas, mas também determinando quando e onde irão agir. Esse direcionamento dos ataques à jovem aponta para um cerceamento do indivíduo nesse mundo. Ao falar sobre o papel da monstruosidade no Gótico, Punter e Byron também apontam que

Através da diferença, seja na aparência ou no comportamento, os monstros servem para definir e construir as políticas do 'normal'. Localizados nas margens da cultura, eles policiam os limites do humano, apontando para as linhas que não devem ser cruzadas. (PUNTER; BYRON, 2004, p.263) ${ }^{12}$

Essa ideia encontra eco também em "A cultura dos monstros: sete teses", de Cohen (2000, p.41), que afirma que uma das funções do monstro é impedir "a mobilidade (intelectual, geográfica ou sexual), delimitando os espaços sociais através dos quais os corpos privados podem se movimentar". O monstro como elemento regulador é recorrente no Gótico - especialmente em sua vertente mais tradicional -, o que já o posiciona como um mecanismo de controle, sendo algo que permanece e que pode ser observado também em Jogos Vorazes (s). No caso dos homens-lagartos isso ganha uma dimensão literal, já que seu trabalho é justamente impedir que Katniss e seu grupo de resistência usem os esgotos para adentrar a Capital e encontrar o presidente Snow, mas também pode ser visto no caso da arena.

12 No original: "Through difference, whether in appearance or behaviour, monsters function to define and construct the politics of the 'normal'. Located at the margins of culture, they police the boundaries of the human, pointing to those lines that must not be crossed." 
Fica evidente, durante a leitura, que os responsáveis pelos jogos querem que os sobreviventes identifiquem os outros tributos $^{13}$ - como visto na citação em que descreve os bestantes, Katniss inicialmente os reconhece pela coleira que carrega o número de seus distritos de origem, mas a aparência de cada um dos animais foi construída com base nas características de quando eram humanos, o que inclui os olhos. Esses bestantes deixam particularmente clara a extensão do controle do estado, pois mostram que a Capital tem o poder de fazer o que desejar com os indivíduos e seus corpos, e que nem a morte coloca um fim nessa dominação; na verdade, ela gera novas possibilidades de moldar e manipular esses corpos.

$\mathrm{O}$ desvelamento da verdadeira origem dessas criaturas faz com que elas se tornem uma mensagem, uma demonstração do poder do qual ninguém está livre, o que novamente se relaciona à tese de Cohen, que afirma também que o monstro nos mostra que sair dos limites permitidos "significa arriscar sermos atacados por alguma monstruosa patrulha de fronteira ou - o que é pior - tornarmo-nos, nós próprios, monstruosos." (2000, p.41). Da mesma forma que os tributos mortos foram transformados em bestantes, Katniss também corre esse risco, e à medida que a narrativa avança, mais a ameaça do monstro vai ficando clara, conforme a protagonista vai se sentindo mais presa aos mecanismos de poder e é levada a confrontar suas escolhas. Em A esperança (2010), livro que conclui a série, a própria Katniss vai refletir sobre esses monstros:

Nenhum bestante é do bem. Todos têm a intenção de causar algum dano a você. Alguns tiram sua 13 Tributo é o nome dado aos jovens que são mandados para competir na arena. 
vida, como os macacos. Outros sua sanidade mental, como as teleguiadas. Entretanto, as verdadeiras atrocidades, as mais assustadoras, incorporam a perversão psicológica elaborada para aterrorizar a vítima. A visão do bestante lobo com os olhos dos tributos mortos. O som dos gaios tagarelas replicando os torturados gritos de Prim. O cheiro das rosas de Snow misturado com o sangue das vítimas. Perceptíveis no esgoto. Fazendo meu coração disparar, minha pele virar gelo, tornando meus pulmões incapazes de sugar o ar. É como se Snow estivesse respirando bem na minha cara, me dizendo que é hora de morrer. (COLLINS, 2011b, p.335)

Vemos, então, que "[m]onstros horrendos são ameaçadores. [...] O monstro também pode ser ameaçador psicológica, moral ou socialmente. Pode destruir a identidade das pessoas" (CARROLL, 1999, p.64), o que na obra conflui em diversas possibilidades de um controle mais eficiente e direcionado dos indivíduos. O Estado escolhe o monstro de acordo com o objetivo que deseja alcançar, e dos limites que se deseja estabelecer. Na citação, Katniss sente como se o presidente Snow, representante máximo desse controle, estivesse em sua presença, o que pode ser lido como uma internalização das estruturas de controle. Foucault, ao falar sobre as formas de controle do sujeito, traz a imagem do panóptico, uma arquitetura feita para "permitir um controle interior, articulado e detalhado - para tornar visíveis os que nela se encontram; mais geralmente, a de uma arquitetura que seria um poder operador para a transformação dos indivíduos" (FOUCAULT, 1999, p.144), e que se caracteriza também pela sensação de constante vigilância a que sujeita os indivíduos. O 
próprio Cohen chama a atenção para o fato de que o monstro é um aliado da sociedade panóptica (2000, p.44), lembrando sua função de policiamento das fronteiras. Para Foucault, quando ocorre a internalização do panóptico, "[a] eficácia do poder, sua força limitadora, passaram, de algum modo, para o outro lado para o lado de sua superfície de aplicação" (1999, p.168), ou seja, os sujeitos se tornam responsáveis pela própria regulamentação: sabendo que estão submetidos "a um campo de visibilidade", eles próprios se mantêm dentro dos parâmetros (1999, p.168). Katniss, aqui, está tentando derrubar as estruturas do poder social - ela está numa missão para matar Snow -, o que inclui quebrar esse ciclo e ultrapassar as "barreiras do possível" impostas. A invocação da figura de Snow nesse momento mostra a dificuldade de quebrar com essa internalização. Os diversos monstros que ela encontrou foram bem-sucedidos no fato de que ela sente que o perigo pode surgir a qualquer momento, porque a ameaça apresentada por eles se mostrou real.

\section{HUMANIDADE E MONSTRUOSIDADE}

Esses monstros mais convencionais, assustadores e repugnantes, não são, porém, a única figuração de monstruosidade na trilogia de Collins. Existem também o que chamaremos de monstros humanos. O monstro humano não é um sujeito que cometeu atrocidades, mas aquele que teve sua humanidade retirada de si. Ao abordar os monstros em distopias que contêm elementos do maquinário gótico, Cartwright remete à ideia de David Seed, para quem existe uma relação entre a monstruosidade e a transformação do homem em algo menos 
ou mais que humano (2005, p.180). Frequentemente, nas obras, vemos pessoas comuns que foram submetidas a eventos e procedimentos que fazem com que sejam vistas como inferiores, logo, o monstro como aquele ser que é menos que humano. Um ser posto à margem, alguém do qual se deve manter distância e que é encarado com receio e até medo, pois incorporou em si a função de alerta do monstro.

Carroll aponta que, em muitos casos, a divisão entre humanidade e inumanidade é "assinalada como ter versus não ter sentimentos" (1999, p.68, grifos do original). Essa relação parece valer em Jogos Vorazes (s), onde o monstro vai ser o nãohumano no sentido daquele que não tem sentimentos. Parte da monstruosidade da Capital provém justamente de seus atos cruéis, que atacam diretamente a condição humana. Mas a relação entre sentimento e monstruosidade na série se entende também na medida em que o monstro é aquele que é privado da empatia e das relações humanas. Isso pode ser visto quando, em dado momento da narrativa, Peeta passa por um condicionamento que o faz odiar Katniss.

- Porque ela está mentindo! Ela é uma mentirosa! Você não pode acreditar em nada do que ela diz! Ela é uma espécie de bestante que a Capital criou para usar contra todos nós! - grita Peeta

- Não, Peeta. Ela não é uma... - tenta Delly mais uma vez.

- Não confie nela, Delly - diz Peeta com uma voz frenética. - Eu confiei e ela tentou me matar. Ela matou meus amigos. Minha família. Nem se aproxime dela! Ela é uma bestante! [...] 
Não apenas ele me odeia e quer me matar, como também deixou de acreditar que sou humana. (COLLINS, 2011b.p.207-208)

As memórias do jovem foram alteradas para fazer com que Katniss parecesse monstruosa, uma pessoa mentirosa capaz de cometer atos horríveis. A partir do momento que ele a entende como um ser sem sentimentos, tudo que ele pode sentir por ela é ódio e repulsa, e, assim, ele para de enxergá-la como humana, chamando-a de bestante.

Esse poder de manipulação por parte do Estado revela outra ansiedade comum do Gótico, a ameaça da desintegração, mais especificamente da ruína do sujeito humano, e das noções tradicionais de subjetividade (HURLEY,2004, p.3).“Esse exercício do poder pelos aparelhos de estado serve para ameaçar a interioridade do indivíduo, se transformando em um pesadelo no processo" (CARTWRIGHT, 2005, p.182) ${ }^{14}$ e se convertendo na possibilidade de qualquer um se transformar em monstro e a monstruosidade do estado surge justamente "da habilidade que ele tem de invadir as barreiras, questioná-las e também reconstruí-las de maneiras novas, abstratas e assustadoras " (CARTWRIGHT, 2005, p.182) ${ }^{15}$. Para Punter e Byron

Textos Góticos chamam atenção, repetidamente, para a natureza construída do monstro, para os mecanismos da produção do monstro, e revelam exatamente como o outro é construído e posicionado ao mesmo tempo como estranho e inferior. Isso, por sua vez, desnaturaliza o humano,

14 No original: "This exercise of power by the state apparatus serves to threaten the interiority of the individual, becoming nightmarish in the process".

15 No original: "from the ability it has to invade boundaries, question them and also restructure them in new, abstract and frightening ways" 
mostrando que o humano supostamente superior é, como a alteridade do monstro, simplesmente um produto de uma luta contínua na construção e reconstrução discursiva do poder. $\left(2004\right.$, p.264) ${ }^{16}$

É justamente isso que vemos em ação em Jogos Vorazes (s), ganhando uma dimensão a mais porque aqui os monstros são um resultado direto do poder, já que sua origem está diretamente ligada ao Estado. Para mostrar a dimensão de seu poder e que nada escapa a ele, ele penetra no sujeito e o destrói.

A estrutura dos romances parece indicar que o próprio ato de se envolver com a Capital, seja a favor ou contra ela, abre a possibilidade de que o sujeito se torne um monstro. Dessa forma, esses monstros humanos revelam ainda a dimensão reguladora do monstro. É um mundo que pede constante vigilância por parte do sujeito para que ele não ultrapasse as fronteiras do permitido.

Um exemplo de sujeitos que perdem sua humanidade por terem transgredido são os Avox, rebeldes e traidores que, após serem capturados, têm sua língua cortada e se tornam servos ou trabalhadores da Capital. Dois dos Avox apresentados na trilogia, Lavinia e Pollux, deixam claro que, nesse caso, o processo de perda da humanidade não se relaciona com a perda dos sentimentos, mas sim do reconhecimento, do status de humano. No primeiro livro, Katniss tem seu primeiro encontro com uma dessas pessoas e aprende que "você não pode se dirigir a eles, a menos que seja para dar alguma ordem" (COLLINS, 2010, p.87), marcando sua condição

16 No original: "Gothic texts repeatedly draw attention to the monster's constructed nature, to the mechanisms of monster production, and reveal precisely how the other is constructed and positioned as both alien and inferior. In turn, this denaturalizes the human, showing the supposedly superior human to be, like the monster's otherness, simply the product of an ongoing struggle in the discursive construction and reconstruction of power." 
sub-humana e invisível. A Avox em questão é Lavinia, cujo nome só será revelado no terceiro livro, sendo que a perda do nome - e, logo, da identidade - pode ser vista como uma forma de reduzir a pessoa a uma função. Mesmo com uma aparência convencional e não assustadora, a Avox desperta uma sensação ruim em Katniss.

Não consigo saber de onde a conheço ou quando a conheci e nem lembrar seu nome. Mas tenho certeza de que a conheço. Os cabelos ruivos, as feições arrebatadoras, a pele branca e lisa como porcelana. Mas, no exato momento em que eu Ihe dirijo as palavras [Eu te conheço], sinto minhas entranhas se contraindo de ansiedade e culpa ao vê-la, e apesar de não saber exatamente o quê, sei que há alguma lembrança desagradável associada a ela. A expressão de terror que está estampada em seu rosto apenas intensifica minha confusão e minha inquietude. Ela balança a cabeça, negando com veemência, e se afasta rapidamente. (COLLINS, 2010, p.86)

De fato, as duas já haviam se encontrado antes: Katniss presenciou o episódio em que a outra jovem foi capturada, em um momento em que ela estava fora dos limites de seu distrito - e ficou apenas observando enquanto a Avox era levada, ignorando seu pedido de socorro. A ideia de que Katniss possa conhecer a moça causa, nas outras personagens, um notável desconforto, com todos tentando reafirmar que não é possível que as duas se conheçam, deixando claro que a mera insinuação de uma conexão entre elas é perigosa.

Um pouco após a Avox se retirar, Katniss reflete sobre a situação e conclui que: "imaginar a garota com a língua mutilada me assusta. Ela me faz lembrar do motivo de eu estar nesse lugar. 
Não para vestir roupas modernosas e comer guloseimas. Mas para sucumbir a uma morte sangrenta enquanto a multidão incentive meu matador" (COLLINS, 2010, p.89).

Talvez a garota não tenha se lembrado de mim. Mas sei que ela se lembrou. Você não esquece o rosto da pessoa que representou sua última esperança. Cubro a cabeça com as cobertas, como se a ação pudesse me proteger da garota ruiva que não pode falar. Mas consigo sentir os olhos dela me encarando, atravessando as paredes e as portas, e as roupas de cama. (2010, p.94-95)

A presença da Avox tem uma dupla função: reforça para Katniss a sua realidade (e o fato de que ela está presa nesse sistema sem possibilidade de fuga), ao mesmo tempo em que a faz repensar sua própria humanidade. Katniss sente que falhou ao deixar que Lavinia fosse capturada, e sua inatividade resultou ainda na morte de uma pessoa, um jovem que também estava fugindo. A protagonista recusou ajuda a alguém em perigo e depois fingiu não a conhecer para não agir diferentemente do que era esperado dela, e essa atitude de autopreservação aparece aqui como algo potencialmente negativo. Ter esse momento de fraqueza reconhecido por outra pessoa faz com ele se torne mais real e assombre Katniss, que é forçada a repensar suas ações. Indiretamente, Katniss foi responsável pela outra jovem ter se tornado uma Avox, que são claramente colocados na narrativa como sendo "menos que humanos", e isso gera um medo inescapável, pois levanta a possibilidade de ela ter o mesmo destino, e também de que algo ainda maior possa ter sido corrompido na outra jovem, que poderia até mesmo se alegrar com sua morte. 
O outro personagem que interessa para a argumentação, Pollux, é um Avox que, após escapar do controle da Capital, se juntou à resistência e passou a integrar a equipe de Katniss no terceiro livro. Quando as personagens precisam seguir caminho nos subsolos da Capital, Pollux serve de guia, e nos é revelado que ele passou cinco anos vivendo e trabalhando no local, sem nunca ver a luz do sol, o que já aponta para as condições subhumanas as quais ele era submetido. Os subsolos são uma estrutura labiríntica - Katniss até mesmo usa a palavra labirinto para se referir a eles -, composta por esgotos, passagens de manutenção, canos e com caminhos e segredos escondidos, que se mostra perigoso para quem não é familiarizado com ele. Essa estrutura pode ser entendida como uma ocorrência de um outro elemento tipicamente gótico em Jogos Vorazes (s), o locus horribilis, A leitura indica que o subsolo foi uma peça chave no processo de desumanização de Pollux, o que parece demonstrar que, na trilogia, o espaço assustador pode se converter em mais um mecanismo para criar monstros. ${ }^{17}$

Nos romances Góticos tradicionais, o labirinto "passou a ser associado com medo, confusão e alienação" (BOTTING, 2005, p.52) ${ }^{18}$. Isso pode ser visto em $A$ esperança:

Jackson diz para eu comer uma lata de comida e ficar de olho em Pollux, que insistiu em montar guarda a noite inteira.

- Ele não consegue dormir.

Eu me arrasto a um estado relativamente alerta,

17 É importante frisar que o objetivo nesse trabalho não é analisar o espaço ficcional por ele mesmo, mas sim os efeitos que ele provoca nas personagens.

18 No original: "came to be associated with fear, confusion and alienation". 
como uma lata de cozido de batata e feijão, e me sento encostada na parede de frente para a porta. Pollux parece completamente desperto. Provavelmente reviveu aqueles cinco anos de prisão a noite toda. (COLLINS, 2011b, p.324)

Voltar ao subsolo provoca uma série de reações físicas em Pollux: assim que eles chegam ele fica "pálido e suado" e se segura ao irmão "[c]omo se pudesse cair se não houvesse alguém para ampará-Io" (COLLINS, 2011b, p.321). Isso deixa transparecer os horrores aos quais ele foi exposto enquanto estava no "labirinto". Uma vez de volta ao local, ele é incapaz de dormir, consumido pelas lembranças, mesmo já conhecendo os segredos do subsolo e sabendo se locomover com perfeição por ele.

Saber a dimensão do mal não é o suficiente, e mesmo já estando livre dos perigos - afinal, ele não é mais um funcionário da Capital - existe sempre a ameaça de que eles irão voltar. Botting afirma que "[o] horror do labirinto e de sua confusão de medos e desejos reside na sua completa separação de todas as normas sociais e total transgressão dos limites convencionais" $\left(2005\right.$, p.52) ${ }^{19}$, e na trilogia podemos ver que ele é o lugar em que atrocidades podem ser cometidas sem que haja nenhum tipo de consequência ao seu perpetrador, e o ser humano pode ser reduzido a uma mera criatura - o lugar da retirada da humanidade -, que vai para sempre carregar em si os efeitos da violência sofrida. Temos então que, enquanto "local de todas as formas de comportamento excessivo, irracional e passional, o labirinto também é o lugar em que a ausência, ou a

19 No original: "[t]he horror of the labyrinth and its confusion of fears and desires lies in its utter separation from all social rules and complete transgression of all conventional limits" 
perda, da razão, sobriedade, decência e moral é exposta em seu horror completo." (BOTTING, 2005, p.54) 20

Outro mecanismo desumanizador que pode ter sua estrutura comparada com um labirinto é a arena dos jogos. Os tributos são colocados em uma estrutura fechada e desconhecida, que pode ter qualquer tipo de clima e vegetação, e onde não sabem nem mesmo se encontrarão comida ou água. Apesar de terem liberdade para se movimentar, há o perigo constante de que outro competidor irá aparecer e iniciar um embate, e existe uma equipe de pessoas que monitora o ambiente e seus ocupantes e que tem o poder de causar uma série de eventos para direcionar e forçar a ação. Os tributos, em sua grande maioria, vão para lá contra a sua vontade, e entrar é quase uma garantia de se tornar um assassino.

- Não sei bem como dizer isso. É que... quero morrer como eu mesmo. Isso faz algum sentido? - pergunta ele. Balanço a cabeça. Como ele poderia morrer a não ser como ele mesmo? - Não quero que eles mudem meu jeito de ser na arena. Não quero ser transformado em algum tipo de monstro que sei que não sou.

Mordo o lábio, sentindo-me inferior. Enquanto eu estava ruminando acerca da disponibilidade de árvores, Peeta estava lutando para saber como faria para manter a identidade. Seu eu puro.

- Você está querendo dizer que não vai matar ninguém?

- Não, quando surgir a oportunidade, tenho certeza de que vou matar como qualquer outro tributo.

20 No original: "place of all forms of excessive, irrational and passionate behaviour, the labyrinth is also the site in which the absence or loss of reason, sobriety, decency and morality is displayed in full horror". 
Não posso cair sem lutar. Só fico desejando que haja alguma maneira de... de mostrar à Capital que eles não mandam em mim. Que sou mais do que somente uma peça nos Jogos deles. (COLLINS, 2010, p.156)

No diálogo, Peeta relata o desejo de preservar sua identidade, "seu eu puro", algo que o próprio jovem reconhece ser impossível. A estrutura dos jogos e da arena força os sujeitos a abrirem mão de qualquer integridade, pois em algum momento será necessário entrar em confronto. Aqui, vemos que aquele que mata é um monstro, "menos que humano", e a arena, responsável por essa transformação, se torna então o lugar da perda da razão e da moralidade. Resta apenas determinar o quão longe essa deterioração irá - como no caso de um tributo de anos anteriores que sucumbiu ao canibalismo - e quando isso irá acontecer: Katniss, focada em sobreviver, já parece ter renunciado alguns de seus princípios, sendo hostil com Peeta no resto da cena, mas também fica na defensiva, o que demonstra um conflito interno referente à situação.

Vemos também que sair do labirinto não traz nenhuma resolução ou reestabelecimento da ordem, e tampouco restaura a humanidade do sujeito. No segundo livro da série, somos apresentados aos vitoriosos de outras edições dos jogos e às marcas que essa experiência deixou neles: alguns desses personagens enlouqueceram, outros se tornaram dependentes químicos. Há também um grupo de vitoriosos que parecem ter sido inseridos na vida da Capital, mas na verdade se tornaram produtos nas mãos do governo, sendo vendidos e prostituídos para pessoas influentes. O estado monstruoso garante que não exista 
nenhum tipo de pureza ou integridade no sujeito, adentrando-o, fragmentando sua identidade e se apossando de seu corpo, mostrando a inevitabilidade da perda do eu, transformando os sujeitos em monstros para dominá-los - um exemplo disso pode ser visto em Peeta. O desejo do jovem de manter sua integridade o ajudou a sair da arena dos jogos sem, de fato, matar ninguém, e mesmo que a experiência tenha deixado marcas negativas nele, sua essência havia sido preservada. Porém, na ocasião em que foi sequestrado e passou por uma lavagem cerebral, mudanças profundas ocorreram em seu interior, fazendo com que ele se transformasse praticamente em outra pessoa, adquirindo também uma dimensão monstruosa. Como afirma Cartwright, as distopias são histórias

do anti-herói que luta, ao longo do romance, para resistir as forças que operam dentro de si e de sua ideologia, mas eventualmente acaba por criar uma coisa horrenda e fora de seu controle, ou se torna uma coisa horrenda e fora de seu controle. (2005, p.205, grifos do original) ${ }^{21}$

Nem mesmo as pessoas que estão integradas à ordem dominante estão seguras da ameaça da monstruosidade. É o caso de Tigris, uma antiga estilista dos jogos que caiu em ostracismo após passar por uma série de cirurgias que lhe deram a aparência de um tigre. Alterações cosméticas exóticas são comuns na Capital, mas, nas palavras de Katniss, "ela deve ter feito diversas operações e ultrapassado o limite que separa a normalidade da repelência" (COLLINS, 2011b, p.343). Vemos aqui sendo usada

21 No original: "of the anti-hero who strives throughout the novel to resist the forces at work within himself and his ideology, but eventually either creates something hideous and outwith his control or becomes something hideous and outwith his control". 
a expressão "ultrapassar o limite", e vemos que o resultado de ignorar esse alerta é se tornar um ser grotesco e mutilado, repelente; em outras palavras, um monstro. A animalização de Tigris faz com que ela perca sua humanidade, literalmente, uma vez que ela adquire trejeitos felinos, e figurativamente, pois passa a ter uma feição monstruosa que resulta em um isolamento da sociedade. Temos então que o controle sobre o indivíduo é tão intenso, e a sociedade tão restritiva que sair do limite aceitável não é apenas fácil, como pode acontecer até mesmo quando se tenta seguir o padrão.

Esses monstros humanos, porém, são apresentados para o leitor de forma a inspirar sua empatia. Isso parece estar de acordo com mudanças ocorridas na representação de monstruosidades em obras góticas mais recentes, em que um deslocamento de perspectiva e no foco da empatia vem ocorrendo (PUNTER, BYRON, 2004, p.265). O que temos atualmente é que "não mais um objeto de ódio ou medo, o outro monstruoso se converte em fonte de simpatia, desejo e autorreconhecimento" (BOTTING, 2002, p.286) 22 . Tigris, com sua feição assustadora se mostra um ser gentil, assim como Pollux estabelece um vínculo de afeto com Katniss - esses seres que foram excluídos do convívio social se mostram dignos de sentimentos positivos, e aparecem como vítimas de um sistema. Se, para Carroll, uma das coisas que torna o monstro assustador é que ele busca destruir a ordem moral (1999, p.64), o que vemos em Jogos Vorazes (s) é que o monstro não ameaça a ordem, mas resulta da opressão necessária para mantê-la e também age para a sua manutenção.

22 No original: "no longer objects of hate or fear, monstrous others become sites of identification, sympathy, desire, and self-recognition" 


\section{CONCLUSÃO}

Ao longo do trabalho, buscou-se analisar a figura dos monstros na série de Collins, a fim de definir sua função na narrativa. Parece claro que existe uma relação forte entre o poder e a monstruosidade, que se faz presente em diferentes níveis. Primeiramente, temos o próprio Estado enquanto entidade monstruosa - representado pela figura de Snow -, que aponta para a perversão e a crueldade daquele sistema. Associado a isso, esse governo se ocupa ele mesmo em criar monstros como parte de suas estratégias de controle e dominação, como é o caso dos bestantes.

Há, em Jogos Vorazes (s), um duplo movimento no que se refere à monstruosidade. No âmbito da narrativa, ela segue a função do Gótico tradicional de demarcar os limites e alertar para os perigos de ultrapassá-lo; para o leitor, ela aponta para a crueldade inerente ao sistema representado. Se lembrarmos que as distopias funcionam como uma espécie de cautionary tale, que usa uma projeção no futuro para advertir sobre as condições problemáticas do presente, o monstro serve para mostrar para o leitor que é preciso agir antes que sua criação se torne possível.

A empatia pelos monstros humanos, então, é necessária para quebrar o ciclo que movimenta esse mundo ficcional, e isso pode ser visto dentro da trilogia quando, buscando conseguir mais apoiadores, a resistência transmite um depoimento de Finnick, um vitorioso muito querido pelo público da Capital, em que ele relata a sua objetificação e degradação pelas mãos do 
Estado. Uma tentativa de mostrar que, a partir do momento em que você conhece as atrocidades do sistema, não deveria mais ser possível compactuar com ele. O que vemos na obra de Collins é que "monstros anormais se tornam mais humanos enquanto os sistemas que os excluem adquirem formas assustadoras, repressivas e inumanas" (BOTTING, 2002, p.286) ${ }^{23}$, e é a "sociedade, ao invés do indivíduo, que se torna a fonte primária do horror" (PUNTER, BYRON, 2004, p.266) ${ }^{24}$. Essas mudanças, porém, não comprometem a tradicional relação entre o monstro e a demarcação e o estabelecimento de uma moral, pelo contrário, reforçam essa relação ao colocar a presença de monstros como a marca de um mundo já degradado.

Observou-se que, em Jogos Vorazes (s), temos algo semelhante ao que ocorre no Gótico, onde o monstro desempenhava um papel fundamental na construção da crítica que essas obras propunham. É possível perceber que o a monstruosidade se encontra entranhada na estrutura da sociedade distópica descrita, que se ocupa em criar tais figuras justamente para que elas possam tal como visto no Gótico - agir como guardiãs das fronteiras do permitido. Além desse papel, vemos que a ameaça que o monstro representa para a integridade do sujeito se converte aqui no risco de que o indivíduo vire ele próprio um monstro, seja como punição por ir contra a ordem estabelecida ou pelo mero contato com a realidade distópica.

23 No original: "deviant monsters are rendered more humane while the systems that exclude them assume terrifying, persecutory, and inhuman shapes"

24 No original: "society, rather than the individual, becomes a primary site of horror" 


\section{REFERÊNCIAS}

BOTTING, Fred (2002). "Aftergothic: consumption, machines, and black holes". In: HOGLE, Jerrold E (Ed.). The Cambridge Companion to Gothic Fiction. Cambridge: Cambridge University Press, p.277-300.

(2005). Gothic. Londres, Nova lorque: Routledge.

CARTWRIGHT, Amy (2005). The Future is Gothic: Elements of Gothic in Dystopian Novels. Glasgow, 2005. 268f. (Tese - Doutorado). Department of English Literature, University of Glasgow.

CARROLL, Noël (1999). A filosofia do horror ou paradoxos do coração. Roberto Leal Ferreira (Trad.). Campinas: Papirus.

COHEN, Jeffrey Jerome (2000). A cultura dos monstros: sete teses. In: SILVA, Tomaz Tadeu da (Org.). Pedagogia dos monstros: os prazeres e os perigos da confusão de fronteiras. Belo Horizonte: Autêntica.

COLLINS, Suzane (2010). Jogos Vorazes. Rio de Janeiro: Rocco Jovens Leitores. (2011). Em chamas. Rio de Janeiro: Rocco Jovens Leitores. (2011b). A esperança. Rio de Janeiro: Rocco Jovens Leitores.

FOUCAULT, Michel (1999). Vigiar e punir: história da violência nas prisões. 20.ed. Petrópolis, RJ: Vozes.

HURLEY, KELLY (2004). The Gothic body: sexuality, materialism, and degeneration at the fin de siècle. Cambridge: Cambridge University Press.

PUNTER, David; BYRON, Glennis (2004). The Monster. In: The Gothic. Malden: Blackwell Publishing, p.263-267.

SARGENT, Lyman Tower (1994). "The Three Faces of Utopianism Revisited." Utopian Studies, 5(1), 1-37.

VARSAM, Maria (2003). Concrete Dystopia: Slavery and Its Others. In: BACCOLINI, Raffaella; MOYLAN, Tom (Orgs.). Dark Horizons: Science Fiction and the Dystopian Imagination. New York: Routledge, p.203-224. 